Article

\title{
Evaluation of an Integrated Ultrafiltration/Solid Phase Extraction Process for Purification of Oligomeric Grape Seed Procyanidins
}

\author{
Alba Gutierrez-Docio 1@, Paula Almodóvar ${ }^{1,2}$, Silvia Moreno-Fernandez ${ }^{1}$, \\ Jose Manuel Silvan ${ }^{3}\left(\mathbb{D}\right.$, Adolfo J. Martinez-Rodriguez ${ }^{3} \mathbb{D}$, Gonzalo Luis Alonso ${ }^{4}(\mathbb{D})$ and \\ Marin Prodanov ${ }^{1, *}$ \\ 1 Functional Food Ingredients Group, Department of Production and Characterization of Novel Foods, \\ Instituto de Investigación en Ciencias de la Alimentación (CIAL), (CEI, CSIC-UAM), C/Nicolás Cabrera, 9. \\ Campus Cantoblanco, Universidad Autónoma de Madrid, 28049 Madrid, Spain; \\ alba.gutierrez@uam.es (A.G.-D.); palmodovar@pharmactive.eu (P.A.); silvia.moreno@uam.es (S.M.-F.) \\ 2 Pharmactive Biotech Products SL, Parque Científico de Madrid, 28049 Madrid, Spain \\ 3 Microbiology and Food Biocatalysis Group, Department of Biotechnology and Food Microbiology, Instituto \\ de Investigación en Ciencias de la Alimentación (CIAL) (CEI, CSIC-UAM), C/ Nicolás Cabrera, 9. Campus \\ Cantoblanco, Universidad Autónoma de Madrid, 28049 Madrid, Spain; jm.silvan@csic.es (J.M.S.); \\ adolfo.martinez@csic.es (A.J.M.-R.) \\ 4 Cátedra de Química Agrícola, E.T.S.I. Agrónomos y Montes, Universidad de Castilla-La Mancha, Avda. de \\ España s/n, 02071 Albacete, Spain; Gonzalo.Alonso@uclm.es \\ * Correspondence: marin.prodanov@uam.es; Tel.: +34-91-001-79-11
}

Received: 29 May 2020; Accepted: 6 July 2020; Published: 9 July 2020

\begin{abstract}
The effectiveness of a preparative integrated ultrafiltration/solid-phase extraction (UF/SPE) process for purification of oligomeric procyanidins (OPCs) from a crude grape seed extract (GSE) was studied for the first time. The separation of OPCs from polymeric procyanidins (PPCs) by UF was very efficient. The membrane showed an acceptable filtration flux of 6 to $3.5 \mathrm{~L} / \mathrm{h} \cdot \mathrm{m}^{2}$ at $0.5 \mathrm{bar}$ of transmembrane pressure and $95 \%$ recovery of its water flux after chemical cleaning. The process was scalable to a pilot scale. The separation of very polar and ionic species from OPCs by SPE (XAD7HP and XAD16 resins) was also very good, but both adsorbents lost their retention capacities quickly, due probably to irreversible retention of OPCs/PPCs. Even though the global purification of OPCs by the integrated UF/SPE process allowed the recovery of $24.2 \mathrm{~g}$ of highly purified OPCs ( $83 \%$ purity) from $14.4 \mathrm{~L}$ of crude grape seed extract, the use of these adsorbents for further purification of the OPCs was very limited.
\end{abstract}

Keywords: grape seed extract; purification; tangential-flow pressure-driven membrane ultrafiltration; solid-phase extraction; oligomeric procyanidins

\section{Introduction}

Flavanols (catechins and procyanidins) are the most abundant secondary metabolites found in seeds of Vitis vinifera L. species with amounts of up to $6.4 \mathrm{~g} / 100 \mathrm{~g}$ [1]. From a chemical point of view, they are an excellent example of how plants can synthesise an unlimited diversity of structures based on the condensation of only three elemental units: (+)-catechin, (-)-epicatechin and (-)-epicatechin gallate. This diversity is due to some of their particular features: the stereochemistry of the asymmetric carbon atoms $\mathrm{C} 2$ and $\mathrm{C} 3$ of the flavan skeleton, type of interflavan bond (C4-C8 and C4-C6 for B-type procyanidins), the length of the polymer chain (degree of polymerisation), the degree of galloylation 
and the position of the gallic acid ester [2-4] and its ability to form complex structures with other biopolymers, such as polysaccharides and proteins [5].

From a technological point of view, procyanidins grant bitter taste and astringency to red wines [6] and contribute to the stabilisation of their colour and equilibration of their redox state [7]. From a nutritional point of view, they have been considered as antinutrients for a long time because of their capacity to inhibit digestive enzymes [8]. Nowadays, a growing number of studies show that they are rather beneficial for animal [9-11] and human health, covering a large number of activities such as cardioprotective [12], anticarcinogenic [13], or antiaging [14], among others. Most of these activities have been attributed to the high reducing (antioxidant) activity of the procyanidins [15], which is, respectively, 20- and 50-times higher than those of the most studied natural antioxidants, vitamins $\mathrm{C}$ and $\mathrm{E}$ [16]. Besides this, grape seed procyanidins have demonstrated huge antimicrobial $[17,18]$, antiulcer [19], anti-inflamatory [15], or antilithiasis [20] activities, among others.

Nevertheless, it should be pointed out that only monomeric to trimeric flavan-3-ols have been found to cross animal and human intestinal walls at trace concentrations [21-24], while procyanidins, with a higher degree of polymerisation, are not absorbed or, rather, are partially hydrolysed to monomers and dimers in the stomach [25] or transformed to more simple metabolites by gut microbiota [24,26,27]. Some authors have also claimed that the antioxidant activity of procyanidins rises along with the increase in their degree of polymerisation, up to trimers, and afterwards, decreases [28]. All these findings suggest that from a health and nutritional point of view, low molecular mass oligomeric procyanidins (OPCs) are more interesting than those of a higher degree of polymerisation.

The vast structural diversity and content variability of grape seed procyanidins make their separation and determination extremely difficult. In fact, there is not a singular analytical method that can resolve this problem completely. Due to their high to moderate molecular polarities, procyanidins are individually assessed using reverse-phase liquid chromatography. Nevertheless, in spite of the important technical advances achieved in chromatographic separations, such as modern high-performance liquid chromatographs coupled to photodiode arrays and high-resolution mass spectrometry detectors (HPLC-PAD-MS), ultra HPLC-PAD-MS (UPLC-MS), or two-dimensional HPLC-MS, only some major procyanidins of up to heptamers have been separated and, up to tetramers, have been quantified [24,29-31].

For global characterisation of monomer and polymer flavan-3-ols, colourimetric methods are usually used based on their acid depolymerisation in the presence of butanol, condensation with aldehydes, or reaction with specific reagents (Folin-Ciocalteu method), among others [29]. The main problem with these methods is that they have relatively low sensitivity and reproducibility that lead to considerable variations between methods and laboratories. To improve the limitations of these methods, other strategies could be of choice. In this sense, normal-phase (NP) HPLC seems more suitable. This mode of separation is usually used for the analysis of molecules with low polarities but was adapted for the analysis of procyanidins by Rigaud et al. [32]. In such a way, procyanidins elute in order of growing molecular masses and, in the case of cocoa procyanidins, could be quite easy to resolve and quantify, mainly due to the simplicity of their structures (which are based only on the elemental unit (-)-epicatechin). It was later understood that, at this mode of separation, procyanidins precipitate on the head of the column, as they are introduced when the less polar component of the mobile phase is pumped through the column (in which they are not or are slightly soluble), and afterwards, they redissolve gradually with the increase of the more polar component [33], where first, the molecules with lower masses pass in solution and then the bigger ones. Nevertheless, applying NP-HPLC to the analysis of grape seed procyanidins can resolve only procyanidins up to trimers. Separation of higher oligomers is much more difficult because of the widespread overlapping of the galloylated forms of procyanidins with a lower degree of polymerisation on the nongalloylated procyanidins with a higher degree of polymerisation. Therefore, this mode of analysis does not allow a fine separation of grape seed OPCs but does allow the depiction of their profile with an increasing order of molecular masses, as well as the separation of higher molecular mass polymers in a relatively singular peak at 
the end of the chromatogram, making an objective evaluation of the proportion between monomers, oligomers and polymers [34].

Preparative separation of grape seed procyanidins is still more difficult and includes several purification stages in which the number sequence is conditioned by the proposed purity requirements. For initial purification, usually, more unspecific techniques are adopted, such as SEC on relatively inert materials (Sephadex or Toyopearl) [35-37], solvent/nonsolvent precipitation (SNSP) of highly polymerised procyanidins [38] or SPE, preferably performed with synthetic macroporous adsorbents [39]. An alternative to SEC and SNSP is pressure-driven tangential-flow ultrafiltration (UF) that allows relatively good and fast separation of macromolecules, such as procyanidins with a high degree of polymerisation from smaller molecules, including OPCs. Nevertheless, there is only one study in the literature regarding the separation of grape seed procyanidins by UF, with very limited use because it was carried out at an analytical scale [40]. For finer separation, chromatographic techniques with greater resolution capacities are more appropriate. The most important of them are counter-current chromatography [38,41,42] and low/middle-pressure liquid chromatography [35,43]. However, it should be pointed out that these operations are very expensive, and they are used, rather, for obtaining relatively small amounts of procyanidins for testing their biological properties or for analytical reference substances.

Thus, the present study aims to explore the effectiveness of a preparative integrated UF/SPE separation process for obtaining an OPC-rich fraction in the order of grams and possible scaling up to a pilot scale.

\section{Materials and Methods}

\subsection{Materials and Reagents}

The starting material for this work was a concentrated, industrially produced crude grape seed extract (from Output Trade S.L., Villafranca del Penedés, Spain) with 288 NTU of turbidity and $26 \%$ of total soluble substances (TSSs).

For procyanidin purification by UF and SPE by diafiltration, demineralised particle-free water with electrical conductivity of $7-8 \mu \mathrm{S} / \mathrm{cm}$ was obtained inhouse by a Genius 300 reverse osmosis unit (Filtec Depuradoras, Girona, Spain). For HPLC analysis, Milli-Q grade water was produced inhouse by a Milli-Q ${ }^{\circledR}$ Integral 3 purification system (Merck Millipore, Burlington, MA, USA). HPLC grade methanol and acetonitrile were purchased from Scharlab (Barcelona, Spain). Glacial acetic acid (p.a.) was obtained from Sigma-Aldrich (Madrid, Spain) and technical grade acetone and ethanol ( $96 \%$ ) from PanReac AppliChem ITW Reagents (Barcelona, Spain).

\subsection{Equipment}

The crude grape seed extract was clarified by a multifuge 3SR+ centrifuge (Heraeus, SA, Madrid).

The separation of monomeric and oligomeric (OPC) flavan-3-ols from polymeric procyanidins (PPCs) was carried out on a spiral-wound UF membrane cartridge (model Prep/scale-TFF-6, Merck Millipore) with the following technical characteristics: regenerated cellulose, $5.8 \mathrm{~cm}$ in diameter, $39.9 \mathrm{~cm}$ in length, $0.53 \mathrm{~mm}$ of feed spacer, $0.54 \mathrm{~m}^{2}$ of filtration surface and a 10-kDa molecular mass cut-off (MMCO). The membrane cartridge was connected to a pressure-driven tangential-flow UF unit, as described in Muñoz-Labrador et al. [34]. The UF system was operated without external backpressure at a feed flow of $300 \mathrm{~L} / \mathrm{h}$, which gave a tangential flow velocity of $3.1 \mathrm{~m} / \mathrm{s}$ and transmembrane pressure $\left(\mathrm{P}_{\mathrm{TM}}\right)$ of 0.5 bar.

The separation of monomeric and OPC flavan-3-ols from sugars, sugar alcohols, di- and tricarboxylic acids, minerals and other non-adsorptive species (hereinafter referred to as sugars) was carried out on a preparative solid-phase extraction (SPE) unit consisting of a 2-L cylindrical glass tube, provided with a glass frit at the bottom for retaining the stationary phase and a Teflon valve for controlling the mobile phase flow speed. An amount of $1 \mathrm{~L}$ of XAD7HP (macroreticular aliphatic 
acrylic cross-linked polymer) resin from Rohm \& Haas (Philadelphia, PA, USA) was suspended in 1 L of demineralised particle-free water and packed in the column under a constant flow of $150 \mathrm{~mL} / \mathrm{min}$. The resin bed was fixed on the upper side by a 5-mm thick nylon porous tissue (sponge).

\subsection{Preparative Separation Methodologies}

Clarification of the crude grape seed extract was carried out by centrifugation (Figure 1) by lots of $1.5 \mathrm{~L}$ at $4000 \mathrm{rpm}(8570 \times \mathrm{g})$ for $20 \mathrm{~min}$. Turbidity of $0.8 \mathrm{NTU}$ was achieved. The obtained pellet was discarded. The clarified extract was next diluted with demineralised water to $8 \mathrm{~g} / 100 \mathrm{~mL}$ of total soluble substances (TSSs; 15 L) for the following UF treatment.

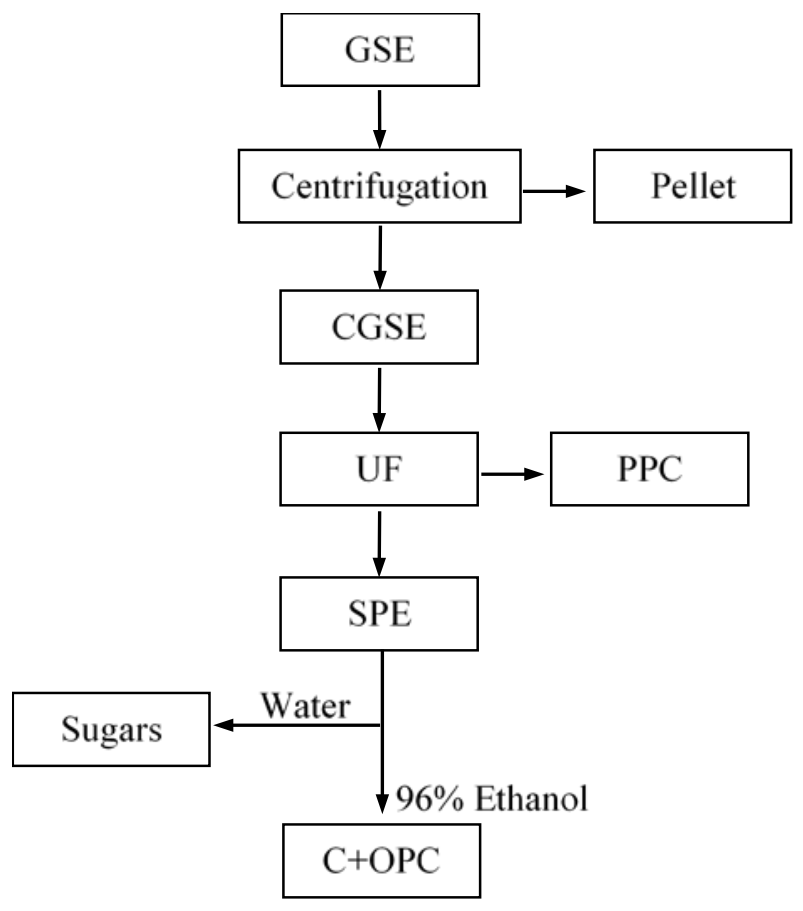

Figure 1. Flow chart of the purification pathway of oligomeric procyanidins from grape seed extract (GSE-grape seed extract, CGSE—clarified GSE, UF-ultrafiltration, SPE-solid phase extraction, PPC - polymeric procyanidin-rich fraction, C—catechins (monomeric flan-3-ols), OPC—oligomeric procyanidin-rich fraction, include some hydroxybenzoic and hydroxycinnamic acids and flavonols, Sugars-sugar-rich fraction, also including sugar alcohols, di- and tricarboxylic acids, minerals, and other very polar and ionic species).

An aliquot of 7.2 L of clarified diluted grape seed extract (CGSE) was ultrafiltered in a continuous concentration mode, at a constant $\mathrm{P}_{\mathrm{TM}}$ of 0.5 bar, without the termostatisation of the system, as described by Silvan et al. [44]. Initially, the UF system was run with $4 \mathrm{~L}$ of CGSE. When $2 \mathrm{~L}$ of filtrate was recovered, $2 \mathrm{~L}$ of new CGSE was added by the use of a peristaltic pump. At the third load, 1.2 L of new CGSE was added. Amounts of 5.2 and $2 \mathrm{~L}$ of permeate and concentrate were obtained, respectively. Monomeric flavan-3-ols and OPCs were recovered with the filtrate. After concentration, purification of the PPCs from OPCs and other small molecules was carried out by diafiltration of the $2 \mathrm{~L}$ of concentrate with the addition of $2 \mathrm{~L}$ of demineralised water in 3 cycles of dilution/concentration (a total of $6 \mathrm{~L}$ of water). The purified PPC fraction (Figure 1) was freeze-dried and stored in the dark at $4{ }^{\circ} \mathrm{C}$. After chemical cleaning of the membrane, a replicate UF with another 7.2 L of GSE was carried out in the same way.

After filtration, the membrane was cleaned by several washes with demineralised particle-free water, followed by recirculation of $0.1 \mathrm{M} \mathrm{NaOH}$ at $45^{\circ} \mathrm{C}$ for $60 \mathrm{~min}$ and the addition of $200 \mathrm{ppm}$ of sodium hypochlorite $(\mathrm{NaClO})$ for an additional $15 \mathrm{~min}$. 
Membrane hydraulic permeability $\left(\mathrm{L}_{\mathrm{p}}\right)$ was determined before $\left(\mathrm{L}_{\mathrm{p}}^{0}\right)$ and after chemical cleaning $\left(\mathrm{L}^{\mathrm{C}}\right.$ ) by plotting the corresponding water flux values, measured at the feed flow-rate of $660 \mathrm{~L} / \mathrm{h}$ and $20^{\circ} \mathrm{C}$ versus the applied $\mathrm{P}_{\mathrm{TM}}$, as described previously [45,46].

Monomeric flavan-3-ols and OPCs were purified from sugar alcohols, di- and tricarboxylic acids, minerals, and other very polar and ionic species by preparative solid-phase extraction (SPE) on $1 \mathrm{~L}$ column of XAD7HP adsorption resin (Rohm \& Haas, Philadelphia, USA). The resin was first conditioned by washing with 2 bed volumes $(2 \mathrm{~L})$ of acetone and 5 bed volumes $(5 \mathrm{~L})$ of demineralised water. An aliquot of $2.5 \mathrm{~L}$ of ultrafiltered grape seed extract $(4.2 \mathrm{~g} / 100 \mathrm{~mL}$ of TSS) was loaded to the resin at a flow rate of $60 \mathrm{~mL} / \mathrm{min}$. Permeate was recovered as a fraction named "sugars". The retentate was diafiltered with demineralised water until $0 \mathrm{~g} / 100 \mathrm{~mL}$ TSS was measured (by refractometry) at the exit of the column. Phenolic compounds were desorbed with $96 \%$ ethanol (C+OPC). The solvent was recovered by distillation at reduced pressure, and the dry extract was redissolved with $50-100 \mathrm{~mL}$ of water, freeze-dried and stored in the dark at $4{ }^{\circ} \mathrm{C}$.

After each separation set, the resin was regenerated with 2 bed volumes $(2 \mathrm{~L})$ of acetone and 5 bed volumes (5 L) of demineralised water. After cleaning, another aliquot of $2.5 \mathrm{~L}$ of PPC-free GSE was treated in the same way. The procedure was repeated 4 times until all the ultrafiltrate volume was treated.

\subsection{Analytical Methodologies}

Total soluble substances (TSSs) in water $\left({ }^{\circ}\right.$ Brix) were measured by the Atago handheld refractometer, calibrated to the interval of 0 to $32 \mathrm{~g} / 100 \mathrm{~mL}$ of TSSs.

PPC s were determined semiquantitatively by NP-HPLC $[33,34]$. For this, relative proportions of OPCs and PPCs were calculated by subtracting the joint area of all oligomeric peaks from those of the whole chromatogram (from the peak corresponding to $\mathrm{PC}_{2} \mathrm{G}$ to the end), assuming that PPCs are the major component of the polymeric fraction that absorb at $280 \mathrm{~nm}$. Purified OPC-rich extract from cocoa was used as a complex reference sample for the identification of nongalloylated OPCs.

Mass transference $\left(\mathrm{M}_{\text {trans }}\right)$ through the studied membrane was calculated for each measured parameter according to $\mathrm{M}_{\text {trans }}=\mathrm{C}_{\mathrm{p}} / \mathrm{C}_{\mathrm{f}} \cdot 100(\%)$, where $\mathrm{C}_{\mathrm{p}}$ and $\mathrm{C}_{\mathrm{f}}$ are the concentration of each parameter in the permeate and feed streams, respectively.

\section{Results and Discussion}

\subsection{Semiquantitative Determination of OPCs and PPCs by NP-HPLC-PAD}

The clarified grape seed extract was analysed by NP-HPLC-PAD. As mentioned above, NP-HPLC does not offer a fine separation of OPCs but does allow us to depict their profile of increasing order of molecular masses, as well as to separate higher polymers in the relatively singular peak at the end of the chromatogram (Figure 4). "Relatively singular peak" comes from the difficult-to-define beginning of the PPC peak because of the existence of an intermedium zone of coelution of oligomers and higher polymers. The use of a cocoa OPC reference material enabled the localization of up to hexamer grape seed nongalloylated OPC peaks. Only those corresponding to nongalloylated and monogalloylated dimers and mono- and digalloylated trimers showed relatively singular resolution (data not shown). Nongalloylated trimers overlapped, most probably with a digalloylated dimer, whereas nongalloylated tetramers overlapped with digalloylated trimers. The rest of the peaks were mixtures of higher nongalloylated and galloylated OPCs. Nevertheless, and in spite of all these limitations, a NP-HPLC chromatogram allows the establishment of a first order of approximation of the relative proportions of OPCs and PPCs. 


\subsection{Separation of Low Molecular Mass (OPCs) from Highly Polymerised Procyanidins (PPCs) by} Tangential-Flow Pressure-Driven Ultrafiltration (UF)

The separation of OPCs from PPCs was carried out by tangential-flow UF. A 10-kDa MMCO membrane from regenerated cellulose was selected according to our previous experience (not published data). Before starting UF, a test of the extract permeability throughout the membrane was carried at $\mathrm{P}_{\mathrm{TM}}$ of 0.25 to 1.0 bar. The response of the permeate flux was linear throughout the whole studied interval. The transference of TSSs throughout the membrane was relatively high, showing a small decrease from $52 \%$ to $47 \%$ with the increase in pressure. Thus, a moderate $\mathrm{P}_{\mathrm{TM}}$ of 0.5 bar was chosen, as it corresponded to an acceptable, expected filtration flux of $6 \mathrm{~L} / \mathrm{hm}^{2}$, a reasonable operation time of 6 to $7 \mathrm{~h}$ and a minor risk for membrane fouling.

\subsubsection{Effect of the UF on the Main Process Parameters}

Two volumes of 7.2 L of GSE were concentrated to $2 \mathrm{~L}$ (a concentration factor of 3.6) and 2 lots of $5.2 \mathrm{~L}$ of ultrafiltrate were obtained in 178 and $168 \mathrm{~min}$ of operation, respectively (Figure 2). The filtration flux decreased from an average value of 6 to $3.5 \mathrm{~L} / \mathrm{h} \cdot \mathrm{m}^{2}$, which corresponds to a $42 \%$ loss compared to the initial flux. The slight periodical rises of the flux were due to the slight dilution of the concentrate with the addition of fresh extract (1-2 L).

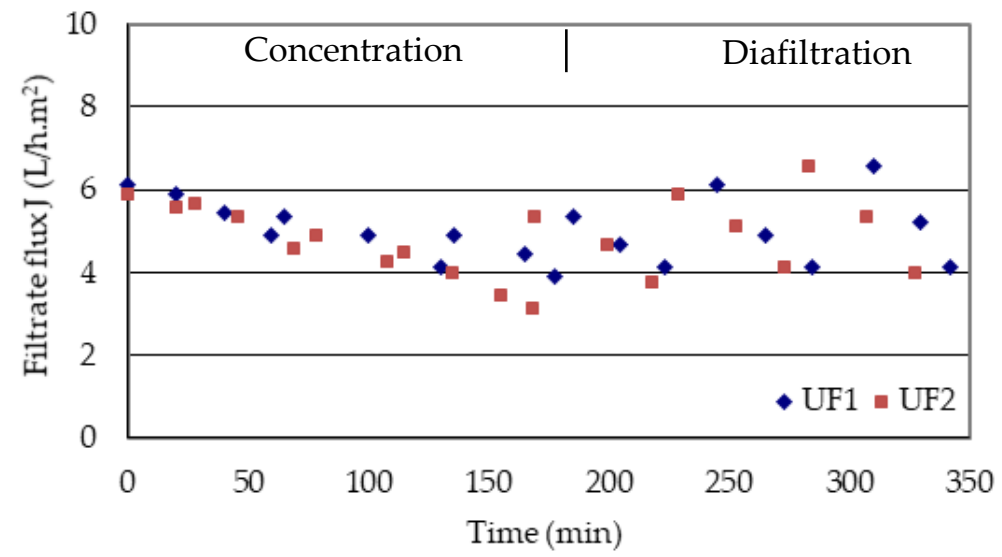

Figure 2. Permeate flux kinetics during UF and diafiltration of both replicates $\left(\mathrm{UF}_{1}\right.$ and $\left.\mathrm{UF}_{2}\right)$ of the studied grape seed extract (GSE) by the $10-\mathrm{kDa}$ MMCO membrane $\left(\mathrm{P}_{\mathrm{TM}} 0.5\right.$ bar, temperature $\left.15-26{ }^{\circ} \mathrm{C}\right)$.

Both concentrates (2 L of each one) were diluted, respectively, with $2 \mathrm{~L}$ of demineralised water and concentrated again to $2 \mathrm{~L}$. This dilution/concentration procedure (diafiltration) was repeated 2 times more to separate the main part of the OPCs and the other molecules with low masses from the retained macromolecular fraction (PPCs) in an additional $170 \mathrm{~min}$. Only 3 cycles of dilution/concentration were carried out in order to minimise oxidation and loss of polymers. The periodical rises of the filtration flux during diafiltration (Figure 2) were due to the dilution of the concentrate with the addition of new volumes of demineralised water $(2 \mathrm{~L})$.

Test of the membrane's hydraulic permeability after standard and forced chemical cleaning showed up to $5 \%$ irreversible loss of permeability.

\subsubsection{Mass Transfer through the Membrane}

Global mass transfer through the 10-kDa MMCO membrane was assessed by handheld refractometer, which allows an easy and fast measurement of the distribution of TSSs into both the permeate and the retentate streams during the whole treatment. The results of this assessment are shown in Figure 3. 


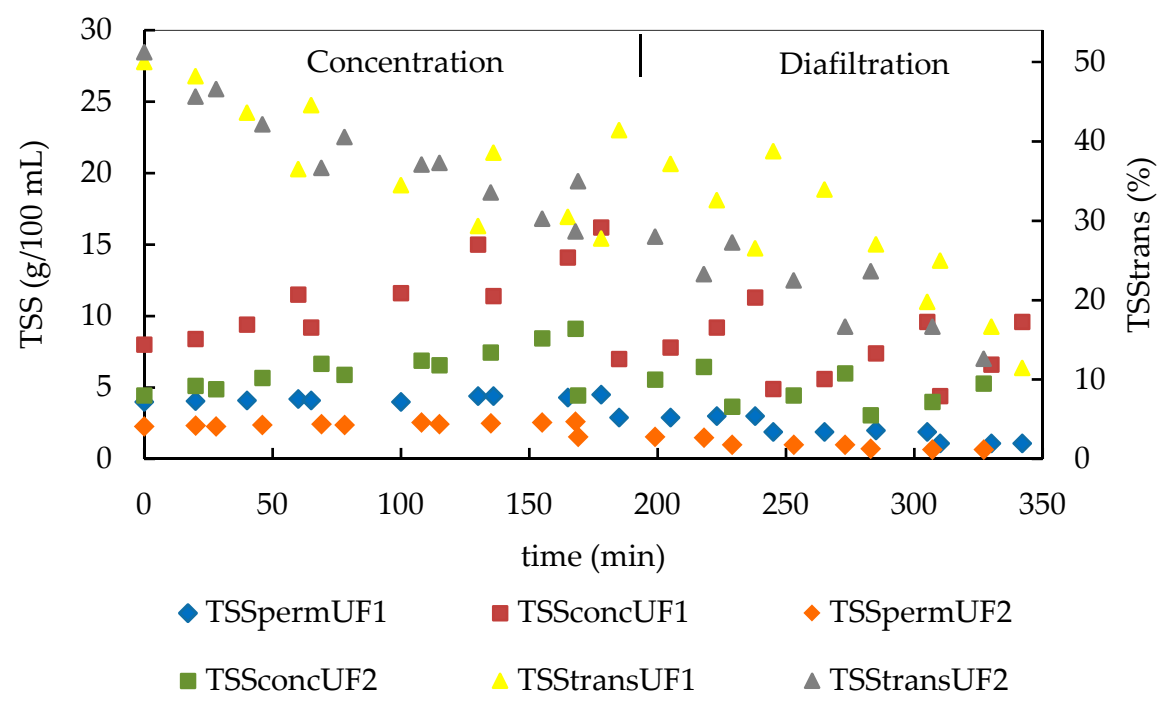

Figure 3. Distribution of total soluble substances (TSSs) in the permeate and concentrate streams and transference of TSSs through the membrane of both replicates $\left(\mathrm{UF}_{1}\right.$ and $\left.\mathrm{UF}_{2}\right)$ of the studied GSE during UF and diafiltration by a 10-kDa MMCO membrane.

At the beginning of UF, 4.2 of the $8 \mathrm{~g} / 100 \mathrm{~mL}$ of the TSS content of the initial GSE (47.5\%) passed into the permeate flow (Figure 3). The remaining high molecular mass TSSs were concentrated in the retentate stream, reaching an average value of $16.3 \mathrm{~g} / 100 \mathrm{~mL}$ at the end of the concentration phase, which is an increase of more than $100 \%$. The small periodical decreases of TSS content in the concentrate flow were due to the dilutions produced by the addition of fresh extract. Contrary to this, the TSS content in the permeate flow showed a very low increase from 4 to $4.6 \mathrm{~g} / 100 \mathrm{~mL}$, which is a direct result of their continuous increase in the retentate stream. These results also indicate a global decrease in mass transfer (TSStrans) during the concentration phase, from $50 \%$ to $28 \%$. This decrease could be attributed mainly to the increase of the TSS content in the concentrate; however, the increase in temperature from 15 to $26^{\circ} \mathrm{C}$ should also be considered.

The diafiltration process produced an overall decrease of the TSS content in both permeate and concentrate flows due to the continuous removal of low molecular mass species with the permeate. The TSS content of the concentrate decreased from $16.3 \mathrm{~g} / 100 \mathrm{~mL}$ at the end of the concentration phase to $9.6 \mathrm{~g} / 100 \mathrm{~mL}$ at the end of the diafiltration, while those of the permeate decreased from 4.6 to $1.2 \mathrm{~g} / 100 \mathrm{~mL}$. The periodical decreases of the TSS content of the concentrate were due to the dilution of the concentrate by the addition of water. The mass transfer showed still more marked decreases, reaching values of $6-13 \%$ at the end of the diafiltration of both replicates (Figure 3). In this case, this effect should be related mainly to the overall decrease of TSS concentration caused by the dilution with water, which also diminishes the effect of the concentration after water loadings and the temperature increase.

Quantitative mass balance of the UF showed that $14.4 \mathrm{~L}$ of clarified grape seed extract with $8 \mathrm{~g} / 100 \mathrm{~mL}$ of TSSs was transformed into $10 \mathrm{~L}$ of ultrafiltrate with $4.2 \mathrm{~g} / 100 \mathrm{~mL}$ of TSSs and $4 \mathrm{~L}(2 \times 2 \mathrm{~L})$ of purified macromolecules (diafiltered concentrate; $0.4 \mathrm{~L}$ were stored for analytical needs). This means that, theoretically, $47.5 \%$ of the whole dry matter of the extract corresponds to macromolecules. Nevertheless, freeze-drying of the diafiltered concentrate gave $106.1 \mathrm{~g}$ of dry powder, which means a recovery of just $20 \%$. This result suggests that diafiltration with only 3 cycles of dilution/concentration with water produced an $80 \%$ loss of macromolecules and that this loss will be higher if higher purity is required.

Afterwards, the mass transfer of catechins and procyanidins through the membrane was assessed by NP-HPLC-PAD. Figure 4 shows an overlay of the chromatograms of CGSE, the final permeate and the final concentrate after GSE UF. 


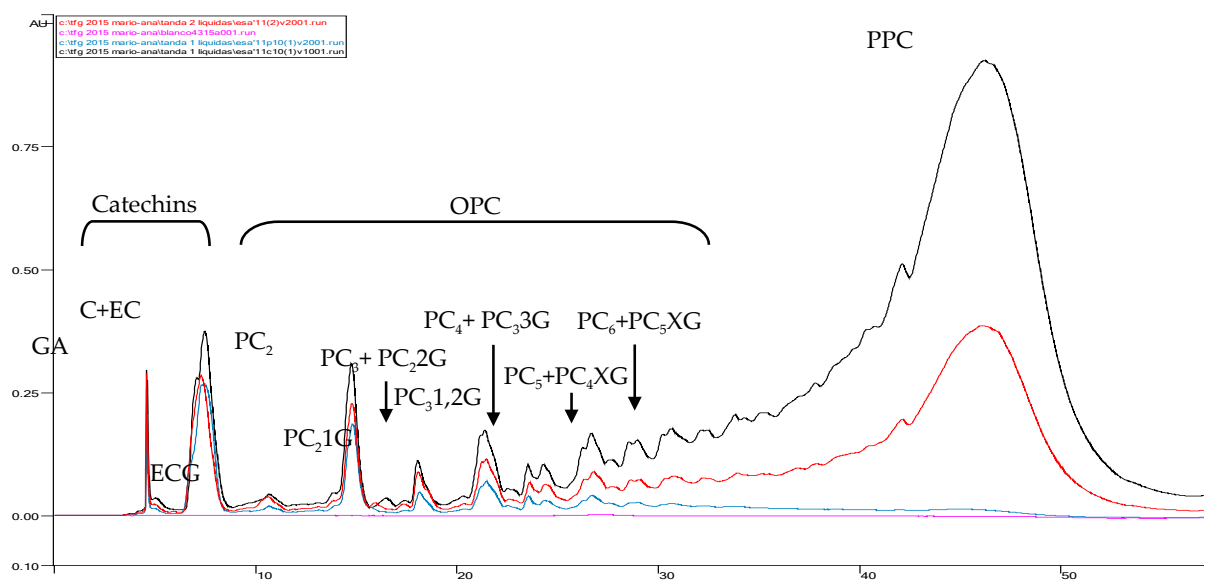

Figure 4. Overlay of NP-HPLC-PAD chromatograms $(280 \mathrm{~nm})$ of the initial (clarified) grape seed extract (GSE; red), the final permeate (blue), the final concentrate (black) and the HPLC baseline (violet) after GSE fractionation by a 10-kDa MMCO membrane (data refer to one replicate). $\mathrm{GA}$ - gallic acid, $\mathrm{C}+\mathrm{EC}$ - catechin and epicatechin, $\mathrm{ECG}$ - epicatechin gallate, $\mathrm{PC}_{2}$ to $\mathrm{PC}_{6}$ - procyanidin dimers to hexamers, $\mathrm{PC}_{2} 1 \mathrm{G}$ - monogaloylated procyanidin dimer, $\mathrm{PC}_{2} 2 \mathrm{G}$-digaloylated procyanidin dimer, $\mathrm{PC}_{3} 1,2 \mathrm{G}$ - mono- and digaloylated procyanidin trimers, $\mathrm{PC}_{3} 3 \mathrm{G}$ - trigaloylated procyanidin trimer, $\mathrm{PC}_{4} \mathrm{XG}$ and $\mathrm{PC}_{5} \mathrm{XG}$-multigaloylated procyanidin tetramers and pentamers, $\mathrm{OPC}$-oligomeric procyanidins, $\mathrm{PPC}$ - polymeric procyanidins.

As it can be seen, at the end of the concentration phase of the UF (the final concentrate of Figure 4, corresponding to min 166 of Figures 2 and 3), 29\%, 38\%, 52\%, 71\% and 88\% of catechins, procyanidin dimers, trimers + a digaloylated dimer, tetramers + a trigaloylated trimer and polymers, respectively, were retained in the concentrate stream. This means that the complete separation of oligomeric procyanidins from polymers with this membrane is not possible.

\subsubsection{Quality of Separation between Procyanidin Polymers (PPCs) and Oligomers (OPCs)}

For quality evaluation of the separation of OPCs from PPCs, freeze-dried fractions of the initial clarified GSE, the whole permeate, the concentrate and the diafiltered concentrate were prepared in a concentration of $20 \mathrm{mg} / \mathrm{mL}$ and analyzed by NP-HPLC (Figure 5).

Figure 5 shows that the $10-\mathrm{kDa}$ membrane produced an ultrafiltrate enriched in gallic acid, catechins and procyanidin oligomers of up to tetramers and impoverished in polymers (down to $17 \mathrm{~g} / 100 \mathrm{~mL}$ of total PPCs). On the other hand, the diafiltration produced an enrichment of polymers in the retentate (PPCs) of almost 300\% but also left other low molecular mass compounds (gallic acid, monomeric (catechins) and oligomeric flavan-3-ols, among others) of an average of $15 \%$ in this fraction as impurities [34]. The application of a longer diafiltration process should decrease the amount of these, but the treatment was stopped at this point in order to minimise further losses of PPCs with the diafiltration water. These results suggest that the 10-kDa UF membrane could be used in the purification of catechins and low molecular mass procyanidins (up to tetramers) from higher polymer procyanidins, in addition to the purification of polymer procyanidins from low molecular mass catechins and procyanidin oligomers, assuming the presence of some impurities of polymeric procyanidins in the OPC-rich fraction, as well as some impurities of catechins and oligomeric procyanidins in the PPC-rich fraction. 


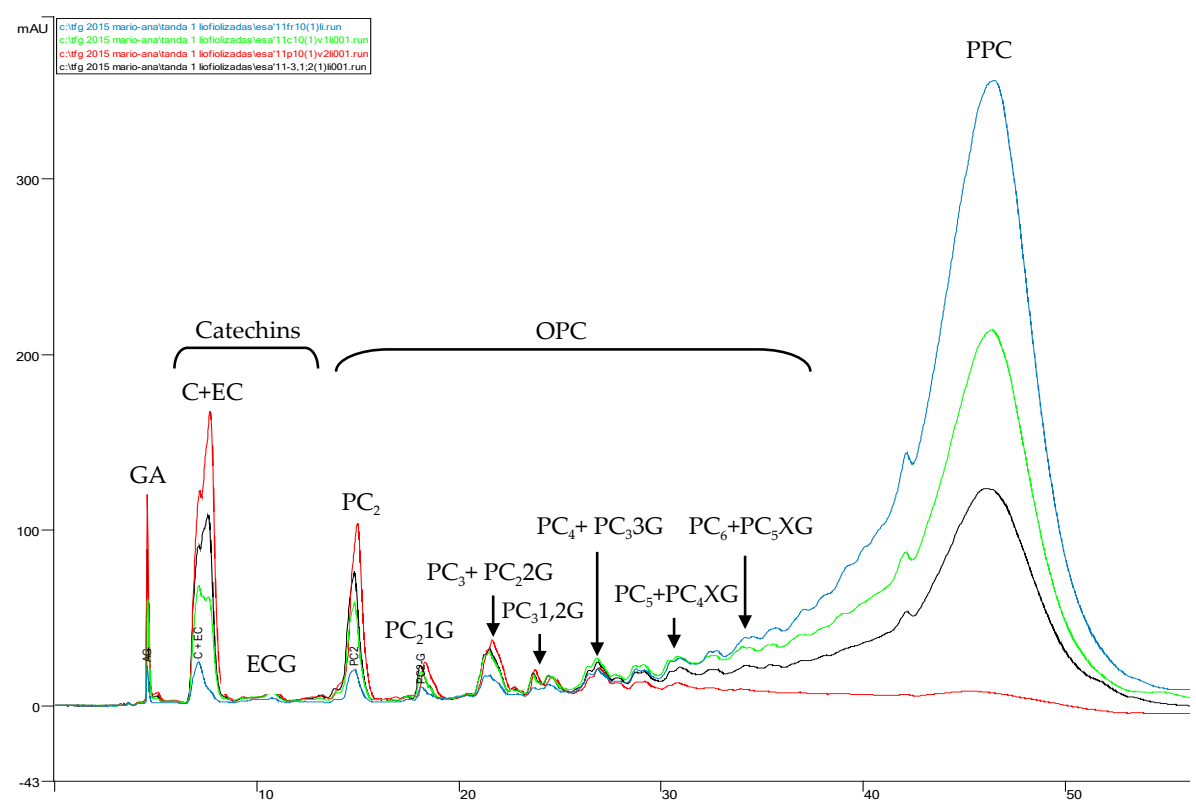

Figure 5. Overlay of the NP-HPLC-PAD chromatograms $(280 \mathrm{~nm})$ of the initial (clarified) grape seed extract (GSE; black), the whole permeate (red), the concentrate (green) and the diafiltered concentrate (blue) after GSE fractionation by the 10-kDa MMCO membrane (data refer to one replicate). GA—gallic acid, $\mathrm{C}+\mathrm{EC}$ - catechin and epicatechin, ECG—epicatechin gallate, $\mathrm{PC}_{2}$ to $\mathrm{PC}_{6}$ - procyanidin dimers to hexamers, $\mathrm{PC}_{2} 1 \mathrm{G}$ - monogaloylated procyanidin dimer, $\mathrm{PC}_{2} 2 \mathrm{G}$-digaloylated procyanidin dimer, $\mathrm{PC}_{3} 1,2 \mathrm{G}$-mono- and digaloylated procyanidin trimers, $\mathrm{PC}_{3} 3 \mathrm{G}$ - trigaloylated procyanidin trimer, $\mathrm{PC}_{4} \mathrm{XG}$ and $\mathrm{PC}_{5} \mathrm{XG}-$ multigaloylated procyanidin tetramers and pentamers, $\mathrm{OPC}$-oligomeric procyanidins, $\mathrm{PPC}$ - polymeric procyanidins.

\subsection{Separation of OPCs from Sugars by Solid-Phase Extraction (SPE)}

The ultrafiltered GSE, containing $4.2 \mathrm{~g} / 100 \mathrm{~mL}$ of TSSs, was further submitted to SPE with $1 \mathrm{~L}$ of resin placed in a column. The treatment was carried out in 4 batches of $2.5 \mathrm{~L} / \mathrm{batch}$. Each permeate was concentrated at reduced pressure to approximately $200 \mathrm{~mL}$ and then freeze-dried. Amounts of 58.9 to $60.3 \mathrm{~g}$ of dry matter were obtained (Table 1 ), which correspond to a $56.1-57.4 \%$ recovery of molecules free-passing through the adsorbent, mainly sugars and minerals. The OPC-rich fractions obtained after desorption with ethanol were also submitted to distillation for ethanol recovery. The dry residues were dissolved in water and freeze-dried to obtain fluid powders. Amounts of 12.7, 11.5, 10.9 and $10.2 \mathrm{~g}$ of dry matter were obtained, respectively, for each batch. Recovery of these fractions was calculated by subtracting the amounts of dry matter entering the resin (per batch) and the amounts recovered in the permeates. Thus, these data were much lower than those obtained for the permeate constituents, ranging in the interval of $12.1 \%$ to $9.7 \%$ (Table 1 ). The low recovery of OPCs suggests that some parts of them are left bonded to the resin matrix. 
Table 1. Total soluble substances per batch (TSS/batch), total soluble substances recovered in the permeate $\left(\mathrm{TSS}_{\text {perm }}\right)$, total soluble substances recovered in the permeate and referred to $100 \mathrm{~g}$

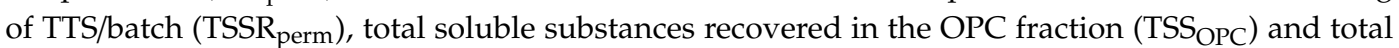
soluble substances recovered in the OPC fraction and referred to $100 \mathrm{~g}$ of TTS/batch (TSSR $\mathrm{OPC}_{\text {) }}$ after solid-phase extraction (SPE) of the ultrafiltered GSE permeate.

\begin{tabular}{cccccc}
\hline SPE $_{\text {batch }}$ & TSS/batch & TSS $_{\text {perm }}$ & TSSR $_{\text {perm }}$ & TSS $_{\text {OPC }}$ & TSSR $_{\text {OPC }}$ \\
\hline & $(\mathrm{g})$ & $(\mathrm{g})$ & $(\%)$ & $(\mathrm{g})$ & $(\%)$ \\
$\mathrm{SPE}_{1}$ & 105 & 58.9 & 56.1 & 12.7 & 12.1 \\
$\mathrm{SPE}_{2}$ & 105 & 59.5 & 56.7 & 11.5 & 10.9 \\
$\mathrm{SPE}_{3}$ & 105 & 60.3 & 57.4 & 10.9 & 10.4 \\
$\mathrm{SPE}_{4}$ & 105 & 59.3 & 56.5 & 10.2 & 9.7 \\
\hline
\end{tabular}

Moreover, the recovery of OPCs showed a trend to decrease with the increase of the number of purification batches, showing that the irreversible bonding of OPCs increases with the number of SPE batches. These results demonstrate that the used resin was progressively losing its adsorption capacity.

Finally, the NP-HPLC-PAD analysis of $20 \mathrm{mg} / \mathrm{mL}$ solutions prepared from the freeze-dried OPC-rich fractions revealed that the initial high recovery of catechins and OPCs from $\mathrm{SPE}_{1}$ decreased slightly after $\mathrm{SPE}_{2}$ and drastically with $\mathrm{SPE}_{3}$ and $\mathrm{SPE}_{4}$ batches, suggesting that the resin was losing not only adsorption capacity but also selectivity of the separation of catechins and OPCs in front of PPCs (Figure 6).

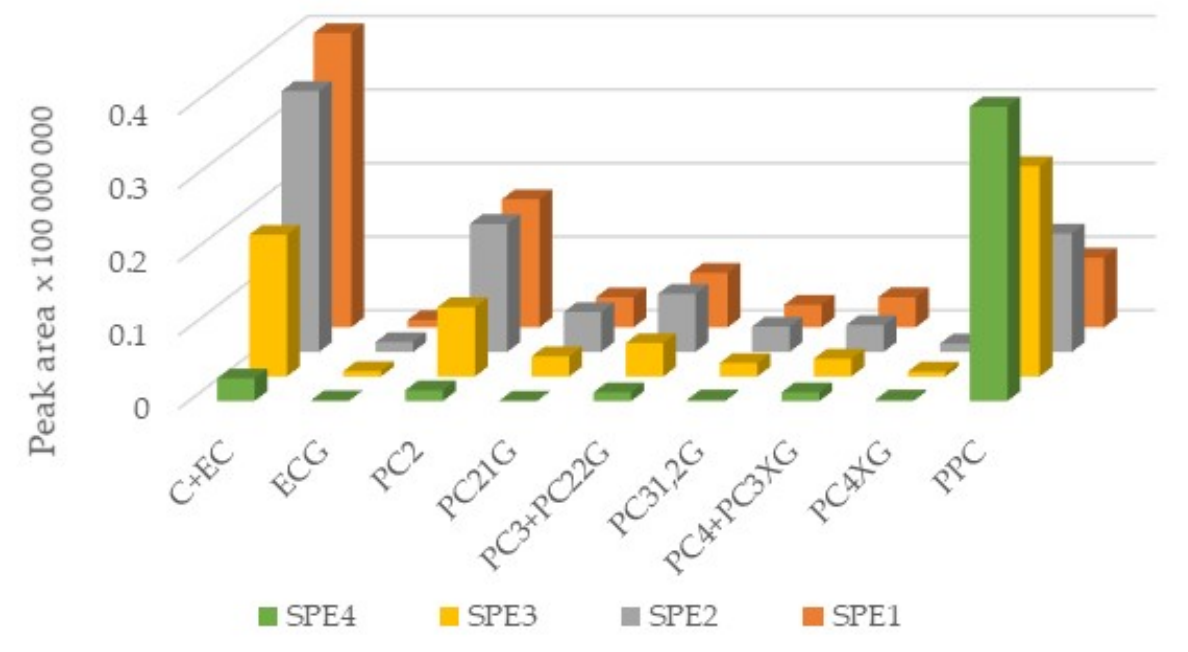

Figure 6. Areas of the peaks (acquired by NP-HPLC-PAD at $280 \mathrm{~nm}$ ) corresponding to monomeric nongalloylated (catechin and epicatechin, C+EC) and galloylated (epicatechin gallate, ECG) catechins to tetrameric multigalloylated $\left(\mathrm{PC}_{4} \mathrm{XG}\right)$ and polymeric procyanidins (PPCs) from the four SPE batches of the GSE ultrafiltrate.

For calculating the quantitative mass balance of the process, only the amounts of species that pass freely through the adsorbent (sugars, sugar alcohols, di- and tricarboxylic acids, minerals and other very polar and ionic species) were taken in consideration. Theoretical recovery of OPCs was calculated by the difference between the amounts of matter entering the resin (per batch) and the amounts of species recovered in the permeates. The results showed that the sugar-rich fraction was more abundant $(30 \%)$ than OPCs $(22.5 \%$ based on the extracted whole dry matter; Figure 7$)$. 


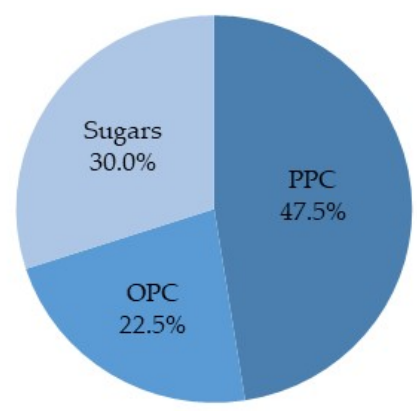

Figure 7. Relative theoretical amounts of the main grape seed components after fractionation by the integrated UF/SPE process.

It is also important to note that all attempts to regenerate the resin with acetone, butanol, $\mathrm{NaOH}$ and $\mathrm{HCl}$ solutions were not effective. Next, the XAD7HP resin was substituted with XAD16 resin, but the loss of adsorption capacity occurred again after 3-4 loads with the same ultrafiltrate. Kammerer et al. had already warned that some polymeric phenols could attach irreversibly to the active sides of adsorption resin and decrease their adsorption capacity in the purification of phenolics from crude plant extracts [47]. That was one of the reasons to remove the PPC fraction first by UF; nevertheless, the results showed that if only macromolecules were responsible for the resin adsorption inhibition, the already done UF clean-up was not efficient enough. These results also suggest that other adsorbent materials should probably be explored as well.

\subsection{Evaluation of the Global Purification of OPCs}

The global effect of purification of OPCs from GSE by both UF and SPE was also assessed by NP-HPLC-PAD, and the obtained results are shown in Figure 8 and Table 2. For simplicity, only the chromatogram of the $\mathrm{SPE}_{1}$ fraction is shown in Figure 8.

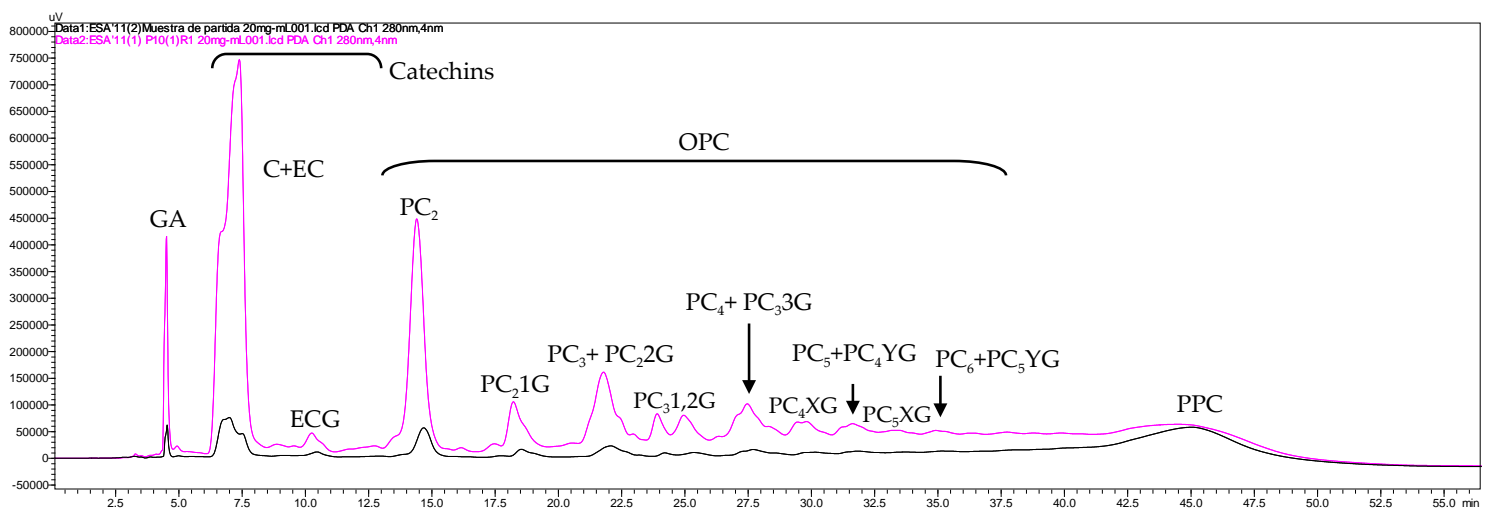

Figure 8. Overlay of NP-HPLC-PAD chromatograms $(280 \mathrm{~nm})$ of $20 \mathrm{mg} / \mathrm{mL}$ reconstituted initial (clarified) grape seed extract (GSE; black) and $20 \mathrm{mg} / \mathrm{mL}$ reconstituted OPC-rich fraction (after $\mathrm{UF}$ and $\mathrm{SPE}_{1}$ ) (magenta) acquired at $280 \mathrm{~nm}$. GA-gallic acid, C+EC—catechin and epicatechin, ECG-epicatechin gallate, $\mathrm{PC}_{2}$ to $\mathrm{PC}_{6}$ - procyanidin dimers to hexamers, $\mathrm{PC}_{2} 1$ Gmonogaloylated procyanidin dimer, $\mathrm{PC}_{2} 2 \mathrm{G}$ - digaloylated procyanidin dimer, $\mathrm{PC}_{3} 1,2 \mathrm{G}$-mono- and digaloylated procyanidin trimers, $\mathrm{PC}_{3} 3 \mathrm{G}$-trigaloylated procyanidin trimer, $\mathrm{PC}_{4} \mathrm{XG}$ and $\mathrm{PC}_{5} \mathrm{XG}$-galoylated procyanidin tetramers and pentamers of low degree of galloylation, $\mathrm{PC}_{4} \mathrm{YG}$ and $\mathrm{PC}_{5} \mathrm{YG}-$ galoylated procyanidin tetramers and pentamers of high degree of galloylation, OPC-oligomeric procyanidins, PPC-polymeric procyanidins. 
Table 2. Flavan-3-ol enrichment (by groups) in purified OPC fractions after UF and after each of the four consecutive SPE batches.

\begin{tabular}{|c|c|c|c|c|}
\hline \multirow[t]{2}{*}{ Flavan-3-ols } & \multicolumn{4}{|c|}{ Flavan-3-ol Enrichment (Folds) } \\
\hline & $\mathrm{SPE}_{1}$ & $\mathrm{SPE}_{2}$ & $\mathrm{SPE}_{3}$ & $\mathrm{SPE}_{4}$ \\
\hline $\mathrm{C}+\mathrm{EC}$ & 9.6 & 8.5 & 4.6 & 0.7 \\
\hline ECG & 4.0 & 5.4 & 2.9 & 0.4 \\
\hline $\mathrm{PC}_{2}$ & 7.8 & 7.8 & 4.2 & 0.6 \\
\hline $\mathrm{PC}_{2} 1 \mathrm{G}$ & 5.6 & 7.4 & 3.7 & 0.1 \\
\hline $\mathrm{PC}_{3}+\mathrm{PC}_{2} 2 \mathrm{G}$ & 5.7 & 6.1 & 3.5 & 0.9 \\
\hline $\mathrm{PC}_{3} 1,2 \mathrm{G}$ & 5.7 & 6.3 & 3.4 & 0.4 \\
\hline $\mathrm{PC}_{4}+\mathrm{PC}_{3} 3 \mathrm{G}$ & 5.3 & 4.7 & 3.1 & 1.5 \\
\hline $\mathrm{PC}_{4} \mathrm{XG}$ & 5.9 & 5.0 & 3.0 & 0.9 \\
\hline $\mathrm{PC}_{5}+\mathrm{PC}_{4} \mathrm{YG}$ & 6.2 & 5.0 & 4.5 & 4.0 \\
\hline $\mathrm{PC}_{5} \mathrm{XG}$ & 5.3 & 4.4 & 3.1 & 1.9 \\
\hline $\mathrm{PC}_{6}+\mathrm{PC}_{5} \mathrm{YG}$ & 3.3 & 2.7 & 2.1 & 4.1 \\
\hline PPC & 0.9 & 1.4 & 2.4 & 3.5 \\
\hline
\end{tabular}

The global effect of purification of OPCs from GSE by the integrated UF/SPE process allowed a general enrichment of all groups of catechins and OPCs (Figure 8, Table 2). This enrichment was higher for the low molecular mass species (catechins and procyanidin dimers), which reached values of 9.6- to 7.8-fold. For the rest of the studied OPCs, the enrichment decreased progressively with the increase of the molecular mass of the procyanidin oligomers. Regarding PPCs, even though they were reduced to more than half of their initial content in the first $\mathrm{SPE}_{1}$ fraction, their proportion increased with each SPE batch due to the loss of adsorption capacity and selectivity of the resin. Figure 8 also shows an overall elevation of the baseline of the HPLC chromatogram of the purified OPC fraction with respect to the clarified GSE, which indicates that there are other molecular species coeluting under the OPCs that cannot be separated at the used chromatographic conditions. Most probably, these species come from the macromolecular PPC fraction, but it is still a challenge to be explored.

Finally, from the $10 \mathrm{~L}$ ultrafiltered GSE, only $24.2 \mathrm{~g}$ of purified OPCs (those obtained from SPE 1 and $\mathrm{SPE}_{2}$ batches) met the requirements for quality acceptance. The rest of them had to be repurified with new resin. Nevertheless, the integrated UF/SPE process produced an OPC-rich powder of high purity (83\% OPCs). The main impurities of this fraction were gallic acid and some other hydroxybenzoic and hydroxycinnamic acids and flavonols (data not shown). It is also important to note that there was no need for the addition of any kind of drying carrier for further stabilisation of the powder because it was fluid and physically stable by itself.

\section{Conclusions}

The effectiveness of a preparative integrated UF/SPE process for the purification of OPCs and PPCs from crude GSE was studied for the first time. Semiquantitative determination of total OPCs and PPCs was carried out by NP-HPLC, also for the first time.

The UF stage was very efficient in the separation of oligomeric (OPCs) from polymeric procyanidins (PPCs), allowing the treatment of 7.2 L of crude, clarified GSE in less than $3 \mathrm{~h}$, with a filtration flux between 6 and $3.5 \mathrm{~L} / \mathrm{h} \cdot \mathrm{m}^{2}$, at $\mathrm{P}_{\mathrm{TM}}$ as low as 0.5 bar. An acceptable purification of the macromolecular (polymeric procyanidin-rich) fraction $(85 \%)$ by diafiltration with water was also possible at the same operating conditions for an additional $3 \mathrm{~h}$. The membrane lost up to $5 \%$ of its hydraulic permeability after chemical cleaning, which is also acceptable, making the process scalable to a pilot scale.

The separation of very polar and ionic species of the grape seed extract, such as sugars, sugar alcohols, di- and tricarboxylic acids and minerals from OPCs by preparative column SPE with XAD7HP and XAD16 resins was also very good. However, both adsorbents lost their adsorption capacities quickly and irreversibly, due probably to the retention of OPCs/PPCs. The treatment produced higher enrichment of monomeric flavan-3-ols and OPCs. The highest increase of 9.6- and 7.8-fold was achieved 
for catechins and procyanidin dimers, respectively. However, the enrichment of OPCs decreased with the increase of the length of the flavanol chain. The obtained results suggest that the use of these resins for further purification of OPCs is possible but very limited and that, probably, other adsorbent materials have to be explored or increased expenses for the restitution of the exhausted resins should be assumed.

The global effect of purification of OPCs from GSE by the integrated UF/SPE process allowed the recovery of $24.2 \mathrm{~g}$ of highly purified OPCs (with $83 \%$ purity) from $14.4 \mathrm{~L}$ of crude grape seed extract. There was no need for the addition of any kind of drying carrier for further stabilisation of the OPC-rich powders because they were fluid and physically stable by themselves.

The quantitative fractionation of the crude grape seed extract by UF/SPE and the use of a semiquantitative NP-HPLC method showed that the main components of the extract were the polymeric procyanidins (47.5\%), whereas the oligomeric procyanidins were as much as $22.5 \%$. It is important to note that the crude grape seed extract also contains an important amount (30\%) of sugars, sugar alcohols, di- and tricarboxylic acids, minerals and other very polar and ionic species that should be taken into consideration as impurities.

Author Contributions: Conceptualization, M.P., A.J.M.-R., and G.L.A.; methodology, M.P., S.M.-F., and P.A.; formal analysis, P.A., A.G.-D., and J.M.S.; investigation, P.A., A.G.-D., S.M.-F., and M.P.; resources, P.A., A.G.-D., S.M.-F., and J.M.S.; writing-original draft preparation, M.P. and P.A.; writing-review and editing, M.P., P.A., and S.M.-F.; visualization, P.A., A.G.-D., and M.P.; supervision, M.P., S.M.-F., and G.L.A.; project administration, M.P. and A.J.M.-R.; funding acquisition, A.J.M.-R. All authors have read and agreed to the published version of the manuscript.

Funding: This research was funded by MINECO (Spain), Project HELIFOOD (AGL2017-89566-R).

Acknowledgments: Paula Almodóvar thanks Pharmactive Biotech Products SL and Consejería de Ciencia, Universidades e Innovación from Comunidad de Madrid (institution) for the financial support of contract IND2019/BIO-17238, Alba Gutiérrez thanks Consejería de Educación e Investigación from Comunidad de Madrid for the financial support of contract PEJ-2018-AI/BIO-11720 and Silvia Moreno thanks Consejería de Educación e Investigación from Comunidad de Madrid for the financial support of contract PEJD-2018-POST/BIO-8797.

Conflicts of Interest: The authors declare no conflict of interest. The funders had no role in the design of the study; in the collection, analyses, or interpretation of data; in the writing of the manuscript, or in the decision to publish the results.

\section{References}

1. Mané, C.; Souquet, J.M.; Ollé, D.; Verriés, C.; Váran, F.; Mazerolles, G.; Cheynier, V.; Fulcrand, H. Optimization of simultaneous flavanol, phenolic acid, and anthocyanin extraction from grapes using an experimental design: Application to the characterization of champagne grape varieties. J. Agric. Food Chem. 2007, 55, 7224-7233. [CrossRef]

2. Santos-Buelga, C.; García-Viguera, C.; Tomás-Barberán, F.A. On-line identification of flavonoids by HPLC coupled to diode array detection. In Methods in Polyphenol Analysis; Santos-Buelga, C., Williamson, G., Eds.; The Royal Society of Chemistry: Cambridge, UK, 2003; pp. 92-127.

3. Dixon, R.A.; Xie, D.Y.; Sharma, S.B. Proanthocyanidin-A final frontier in flavonoid research? New Phytol. 2005, 165, 9-28. [CrossRef] [PubMed]

4. Prodanov, M.; Vacas, V.; Hernández, T.; Estrella, I.; Amador, B.; Winterhalter, P. Chemical characterisation of Malvar grape seeds (Vitis vinifera L.) by ultrafiltration and RP-HPLC-PAD-MS. J. Food Compost. Anal. 2013, 31, 284-292. [CrossRef]

5. Saura-Calixto, F.; Goñi, I.; Mañas, E.; Abia, R. Klason lignin, condensed tannins and resistant protein as dietary fibre constituents: Determination in grape pomaces. Food Chem. 1991, 39, 299-309. [CrossRef]

6. Ferrer-Gallego, R.; García-Marino, M.; Hernández-Hierro, J.M.; Rivas-Gonzalo, J.C.; Escribano-Bailón, M.T. Statistical correlation between flavanolic composition, colour and sensorial parameters in grape seed during ripening. Anal. Chim. Acta 2010, 660, 22-28. [CrossRef]

7. Hidalgo, J. Fenómenos coloidales y clarificación por encolado de los vinos. In Tratado de Enología; Hidalgo, J., Ed.; Ediciones Mundi-Prensa: Madrid, Spain, 2003; pp. 1065-1114. 
8. Appel, H.M. Phenolics in ecological interactions: The importance of oxidation. J. Chem. Ecol. 1993, 19, 1521-1552. [CrossRef]

9. Min, B.R.; Barry, T.N.; Attwood, G.T.; McNabb, W.C. The effect of condensed tannins on the nutrition and health of ruminants fed fresh temperate forages: A review. Anim. Feed Sci. Tech. 2003, 106, 3-19. [CrossRef]

10. Mueller-Harvey, I. Unravelling the conundrum of tannins in animal nutrition and health. J. Sci. Food Agric. 2006, 86, 2010-2037. [CrossRef]

11. Viveros, A.; Chamorro, S.; Pizarro, M.; Arija, I.; Centeno, C.; Brenes, A. Effects of dietary polyphenol-rich grape products on intestinal microflora and gut morphology in broiler chicks. Poult. Sci. J. 2011, 90, 566-578. [CrossRef]

12. Razmaraii, N.; Babaei, H.; Nayebi, A.M.; Assadnassab, G.; Helan, J.A.; Azarmi, Y. Cardioprotective effect of grape seed extract on chronic doxorubicin-induced cardiac toxicity in Wistar rats. Adv. Pharm. Bull. 2016, 6, 423-433. [CrossRef]

13. Zhang, X.Y.; Li, W.G.; Wu YJZheng, T.Z.; Li, W.; Qu, S.Y.; Liu, N.F. Proanthocyanidin from grape seeds potentiates anti-tumor activity of doxorubicin via immunomodulatory mechanism. Int. Immunopharmacol. 2005, 5, 1247-1257. [CrossRef] [PubMed]

14. Balu, M.; Sangeetha, P.; Murali, G.; Panneerselvam, C. Modulatory role of grape seed extract on age-related oxidative DNA damage in central nervous system of rats. Brain Res. Bull 2006, 68, 469-473. [CrossRef] [PubMed]

15. Charradi, K.; Mahmoudi, M.; Bedhiafi, T.; Jebari, K.; El May, M.V.; Limam, F.; Aouani, E. Safety evaluation, anti-oxidative and anti-inflammatory effects of subchronically dietary supplemented high dosing grape seed powder (GSP) to healthy rat. Biomed. Pharmacother. 2018, 107, 534-546. [CrossRef] [PubMed]

16. Bagchi, D.; Garg, A.; Krohn, R.L.; Bagchi, M.; Tran, M.X.; Stohs, S.J. Oxygen free radical scavenging abilities of vitamins $\mathrm{C}$ and $\mathrm{E}$, and a grape seed proanthocyanidin extract in vitro. Res. Commun. Chem. Pathol. Pharmacol. 1997, 95, 179-189. [CrossRef]

17. Jayaprakasha, G.K.; Selvi, T.; Sakariah, K.K. Antibacterial and antioxidant activities of grape (Vitis vinifera) seed extracts. Int. Food Res. J. 2003, 36, 117-122. [CrossRef]

18. Silván, J.M.; Mingo, E.; Hidalgo, M.; de Pascual-Teresa, S.; Carrascosa, A.V.; Martinez-Rodriguez, A.J. Antibacterial activity of a grape seed extract and its fractions against Campylobacter spp. Food Control 2013, 29, 25-31. [CrossRef]

19. Kim, T.H.; Jeon, E.J.; Cheung, D.Y.; Kim, C.W.; Kim, S.S.; Park, S.H.; Han, S.W.; Kim, M.J.; Lee, Y.S.; Cho, M.L.; et al. Gastroprotective effects of grape seed proanthocyanidin extracts against nonsteroid anti-inflammatory drug-induced gastric injury in rats. Gut Liver 2013, 7, 282-289. [CrossRef]

20. Grases, F.; Prieto, R.M.; Fernández-Cabot, R.A.; Costa-Bauzá, A.; Sánchez, A.M.; Prodanov, M. Effect of consuming a grape seed supplement with abundant phenolic compounds on the oxidative status of healthy human volunteers. Nutr. J. 2015, 14, 94-101. [CrossRef]

21. Prasain, J.K.; Peng, N.; Dai, Y.; Moore, R.; Arabshahi, A.; Wilson, L.; Barnes, S.; Michael Wyss, J.; Kim, H.; Watts, R.L. Liquid chromatography tandem mass spectrometry identification of proanthocyanidins in rat plasma after oral administration of grape seed extract. Phytomedicine 2009, 16, 233-243. [CrossRef]

22. Serra, A.; Macià, A.; Romero, M.P.; Anglés, N.; Morelló, J.R.; Motilva, M.J. Metabolic pathways of the colonic metabolism of procyanidins (monomers and dimers) and alkaloids. Food Chem. 2011, 126, 1127-1137. [CrossRef]

23. Choy, Y.Y.; Waterhouse, A.L. Proanthocyanidin metabolism, a mini review. Nutr. Aging 2014, 2, 111-116. [CrossRef]

24. Sánchez-Patán, F.; Barroso, E.; van de Wiele, T.; Jiménez-Girón, A.; Martín-Alvarez, P.J.; Moreno-Arribas, M.V.; Martínez-Cuesta, M.C.; Peláez, C.; Requena, T.; Bartolomé, B. Comparative in vitro fermentations of cranberry and grape seed polyphenols with colonic microbiota. Food Chem. 2015, 183, 273-282. [CrossRef] [PubMed]

25. Spencer, J.P.E.; Chaudry, F.; Pannala, A.S.; Srai, S.K.; Debnam, E.; Rice-Evans, C. Decomposition of cocoa procyanidins in the gastric milieu. Biochem. Biophys. Res. Commun. 2000, 272, 236-241. [CrossRef] [PubMed]

26. Manach, C.; Williamson, G.; Morand, C.; Scalbert, A.; Rèmèsy, C. Bioavailability and bioefficacy of polyphenols in humans. I. Review of 97 bioavailability studies. Am. J. Clin. Nutr. 2005, 81, 230S-422S. [CrossRef] [PubMed] 
27. Appeldoorn, M.M.; Sanders, M.; Vincken, J.P.; Cheynier, V.; Le Guernevé, C.; Hollman, P.C.H.; Gruppen, H. Efficient isolation of major procyanidin A-type dimers from peanut skins and B-type dimers from grape seeds. Food Chem. 2009, 117, 713-720. [CrossRef]

28. Plumb, G.W.; de Pascual-Teresa, S.; Santos-Buelga, C.; Cheynier, V.; Williamson, G. Antioxidant properties of catechins and proanthocyanidins: Effect of polymerisation, galloylation, and glycosilation. Free Radic. Res. 1998, 29, 351-358. [CrossRef]

29. Hümmer, W.; Schreier, P. Analysis of proanthocyanidins. Mol. Nutr. Food Res. 2008, 52, 1381-1398. [CrossRef]

30. Montero, L.; Herrero, M.; Prodanov, M.; Ibañez, E.; Cifuentes, A. Characterization of grape seed procyanidins by comprehensive two-dimensional hydrophilic interaction $\mathrm{x}$ reversed phase liquid chromatography coupled to diode array detection and tandem mass spectrometry (HILICxRPLC-DAD-MS/MS). Anal. Bioanal. Chem. 2013, 405, 4627-4638. [CrossRef]

31. Lin, L.Z.; Sun, J.; Chen, P.; Monagas, M.J.; Harnly, J.M. UHPLC-PDA-ESI/HRMS ${ }^{n}$ profiling method to identify and quantify oligomeric proanthocyanidins in plant products. J. Agric. Food Chem. 2014, 62, 9387-9400. [CrossRef]

32. Rigaud, J.; Escribano-Bailon, M.T.; Prieur, C.; Souquet, J.M.; Cheynier, V. Normal-phase high-performance liquid chromatographic separation of procyanidins from cocoa beans and grape seeds. J. Chromatogr. A 1993, 654, 255-260. [CrossRef]

33. Prodanov, M.; Vázquez, E.; Amador, B.; Reglero, G. Why proanthocyanidins elute in increasing molecular mass order when analysed by normal phase HPLC? In Proceedings of the Polyphenols Communications 2010, XXV International Conference on Polyphenols (ICP 2010), Montpellier, France, 23-27 August 2010; Volume 2, pp. 594-595.

34. Muñoz-Labrador, A.; Prodanov, M.; Villamiel, M. Effects of high intensity ultrasound on disaggregation of a macromolecular procyanidin-rich fraction from Vitis vinifera L. seed extract and evaluation of its antioxidant activity. Ultrason. Sonochem. 2019, 50, 74-81. [CrossRef] [PubMed]

35. Sun, B.S.; Belchior, G.P.; Ricardo-da-Silva, J.M.; Spranger, M.I. Isolation and purification of dimeric and trimeric procyanidins from grape seeds. J. Chromatogr. A 1999, 841, 115-121. [CrossRef]

36. Sharma, V.; Zhang, C.; Pasinetti, G.M.; Dixon, R.A. Fractionation of grape seed proanthocyanidins for bioactivity assessment. In The Biological Activity of Phytochemicals, Recent Advances in Phytochemicals; Gang, D.R., Ed.; Springer: New York, NY, USA, 2011; pp. 33-46. [CrossRef]

37. Pasini, F.; Chinnici, F.; Caboni, M.F.; Verardo, V. Recovery of oligomeric proanthocyanidins and other phenolic compounds with established bioactivity from grape seed by-products. Molecules 2019, 24, 677. [CrossRef] [PubMed]

38. Köhler, N.; Wray, V.; Winterhalter, P. Preparative isolation of procyanidins from grape seed extracts by high-speed counter-current chromatography. J. Chromatogr. A 2008, 1177, 114-125. [CrossRef]

39. Giori, A.; Anneli, A. Grape Seeds Extracts Obtainable by Fractioning on a Resin. World Intellectual Property Organization Patent WO 2007/0.7037 A1, 15 February 2007.

40. Fernández, K.E.; Paiva, R.; Aspé, E. Purification of grape proanthocyanidins by membrane ultrafiltration. J. Med. Biol. Eng. 2015, 4, 178-183. [CrossRef]

41. Zhang, S.; Li, L.; Cui, Y.; Luo, L.; Li, Y.; Zhou, P.; Sun, B. Preparative high-speed counter-current chromatography separation of grape seed proanthocyanidins according to degree of polymerization. Food Chem. 2017, 219, 399-407. [CrossRef]

42. Phansalkar, R.S.; Nam, J.W.; Chen, S.N.; McAlpine, J.B.; Leme, A.A.; Aydin, B.; Bedran-Russoc, A.K.; Pauli, G.F. Centrifugal partition chromatography enables selective enrichment of trimeric and tetrameric proanthocyanidins for biomaterial development. J. Chromatogr. A 2018, 1535, 55-62. [CrossRef]

43. Appeldoorn, M.M.; Vincken, J.P.; Aura, A.M.; Hollman, P.C.H.; Gruppen, H. Procyanidin dimers are metabolized by human microbiota with 2-(3,4-dihydroxyphenyl)acetic acid and 5-(3,4-dihydroxyphenyl)- $\gamma$-valerolactone as the major metabolites. J. Agric. Food Chem. 2009, 57, 1084-1092. [CrossRef]

44. Silvan, J.M.; Pinto-Bustillos, M.A.; Vázquez-Ponce, P.; Prodanov, M.; Martínez-Rodríguez, A.J. Olive mill wastewater as potential source of antibacterial and anti-inflammatory compounds against the food-borne pathogen Campylobacter. Innov. Food Sci. Emerg. 2018, 51, 177-185. [CrossRef]

45. Cassano, A.; Conidi, C.; Drioli, E. Clarification and concentration of pomegranate juce (Punica granatum L.) using membrane processes. J. Food Eng. 2011, 107, 366-373. [CrossRef] 
46. Prodanov, M.; Aznar, M.; Cabellos, J.M.; Vacas, V.; López, F.; Hernández, T.; Estrella, I. Tangential-flow membrane clarification of Malvar (Vitis vinifera L.) wine: Incidence on chemical composition and sensorial expression. OENO One 2019, 53, 725-739. [CrossRef]

47. Kammerer, D.R.; Carle, R.; Stanley, R.A.; Saleh, Z.S. Pilot-scale resin adsorption as a means to recover and fractionate apple polyphenols. J. Agric. Food Chem. 2010, 58, 6787-6796. [CrossRef] [PubMed]

(C) 2020 by the authors. Licensee MDPI, Basel, Switzerland. This article is an open access article distributed under the terms and conditions of the Creative Commons Attribution (CC BY) license (http://creativecommons.org/licenses/by/4.0/). 